\title{
Social Entrepreneurship
}

Samer Abu-Saifan

\section{Source}

Samer Abu-Saifan. (2012). Social Entrepreneurship: Definition and Boundaries.

doi:10.22215/timreview/523.

The social entrepreneur is a mission-driven individual who uses a set of entrepreneurial behaviours to deliver a social value to the less privileged, all through an entrepreneurially oriented entity that is financially independent, self-sufficient, or sustainable. 